\title{
Effect of endogenous pancreatic glucagon on gastric acid secretion in patients with duodenal ulcer before and after parietal cell vagotomy
}

\author{
F B LOUD, J CHRISTIANSEN*, J J HOLST, B PETERSEN, AND P KIRKEGAARD
}

From Department of Surgery D, Glostrup Hospital, University of Copenhagen, and Department of Medical Physiology C, The Panum Institute, University of Copenhagen, Copenhagen, Denmark

SUMMARY The effect of endogenous pancreatic glucagon on submaximal pentagastrin stimulated gastric acid secretion was studied by infusion of 1 -arginine in patients with duodenal ulcer before and after parietal cell vagotomy without drainage (PCV). Preoperatively infusion of 1-arginine resulted in a marked inhibition of acid secretion, whereas no effect was found postoperatively. Plasma glucagon concentrations were identical pre- and postoperatively, fasting as well as during arginine infusion. Serum gastrin concentration rose after PCV but was unaffected by arginine infusion both pre- and postoperatively. The study demonstrates that intact vagal innervation of the fundic glands is a condition of inhibition of pentagastrin induced acid secretion by pancreatic glucagon released by infusion of l-artinine.

Previous studies have suggested that pancreatic glucagon plays a part in the physiological inhibition of gastric acid secretion. ${ }^{1}$

Glucagon inhibition of gastrin stimulated acid secretion follows non-competitive kinetics, ${ }^{1}$ but the nature of the inhibitory action is otherwise unknown.

There is strong evidence that inhibition of gastric acid secretion by intravenous infusion of 1-arginine is due to release of pancreatic glucagon, as the onset and duration of acid inhibition is synchronised with the rise in plasma glucagon concentration. ${ }^{12}$ The only hormone besides glucagon known to be released by arginine is growth hormone. The effect on acid secretion of this hormone is unknown, but as the release of growth hormone is delayed as compared with glucagon, ${ }^{3}$ it does not coincide with the onset of acid inhibition. Furthermore, patients with acromegaly seem to have raised acid secretion. ${ }^{4}$

As no differences in the release of pancreatic glucagon by arginine or in the effect on acid secretion have been demonstrated between patients with duodenal ulcer and healthy subjects, ${ }^{2}$ the role of intact vagal innervation for acid inhibition by

*Address for correspondence and reprint requests: Dr John Christiansen, Department of Surgery D, Glostrup Hospital, DK-2600 Copenhagen, Denmark.

Received for publication 2 December 1980. endogenous glucagon was investigated in patients with duodenal ulcer. The patients were examined before and after parietal cell vagotomy without drainage (PCV), as this type of vagotomy is unlikely to interfere with the release mechanisms of pancreatic glucagon.

\section{Methods}

\section{PATIENTS}

Twelve patients with duodenal ulcer, nine men and three women, median age 40 years (range 22-58 years) were studied. All gave informed consent.

The patients had well-documented chronic duodenal ulcer disease and a radiologically and endoscopically verified duodenal ulcer. None had any evidence of gastric outlet obstruction or had had any recent complications, such as bleeding or perforation.

The patients had a PCV performed according to a standard technique described elswhere. ${ }^{5}$ It should be emphasised that the main trunks of the vagus nerve were isolated to avoid any injury to these nerves.

The patients were studied before and two to three months after the operation as described below.

EXPERIMENTAL PROCEDURE

After an overnight fast a Levin tube was placed under fluoroscopic control and the stomach was 


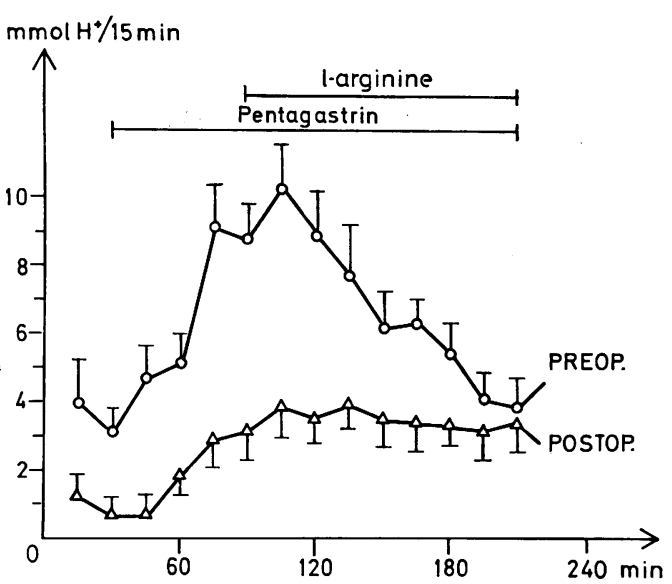

Fig. 1 Gastric acid secretion during infusion of pentagastrin and pentagastrin $+l$-arginine before and after parietal cell vagotomy.

emptied. Gastric juice was aspirated in 15 minute periods by intermittent mechanical suction producing a subatmospheric pressure of $150 \mathrm{~mm}$ mercury and each sample was titrated separately with an autotitrator (Radiometer, Copenhagen) to $\mathrm{pH} 7 \cdot 0$. After a basal secretory period of 30 minutes, pentagastrin was administered by continuous intravenous infusion in a dose of $150 \mathrm{ng} / \mathrm{kg} / \mathrm{h}$ for three hours. This dose of pentagastrin has in previous studies been found to equal $D_{50}$ in normal subjects and does not result in any fade of acid secretion during four hours. ${ }^{1}$ After 60 minutes of pentagastrin stimulation an intravenous infusion of 1-arginine in a dose of $0.6 \mathrm{~g} / \mathrm{kg} / \mathrm{h}$ was added, and continued throughout the study. Blood samples for analysis of pancreatic glucagon, blood glucose, and gastrin were taken from a cubital vein every 15 minutes.

\section{LABORATORY ANALYSIS}

Blood glucose was determined by the hexokinase method. ${ }^{6}$ Pancreatic glucagon and gastrin concentrations were measured radioimmunochemically. The glucagon antiserum (4305) is highly specific for pancreatic glucagon and cross-reacts less than $0.1 \%$ with high concentrations of enteroglucagon and does not cross-react with secretin, VIP, GIP, chole-

Table Acid secretion ( $\mathrm{mmolH}^{+} / 30 \mathrm{~min}$ ) during basal conditions (0-30), during pentagastrin stimulation (90-120) and during pentagastrin stimulation + infusion of l-arginine (180-210) (Mean $\pm S E M)$.

\begin{tabular}{lrl}
\hline Time & \multicolumn{1}{c}{ Preop. } & Postop. \\
\hline $0-30$ & $7 \cdot 1 \pm 1 \cdot 0$ & $2 \cdot 0 \pm 0 \cdot 4$ \\
$90-120$ & $19 \cdot 2 \pm 1 \cdot 3$ & $7 \cdot 8 \pm 0 \cdot 7$ \\
$180-210$ & $7 \cdot 8 \pm 0 \cdot 8$ & $7 \cdot 7 \pm 0 \cdot 7$ \\
\hline
\end{tabular}

cystokinin, or gastrin. ${ }^{7}$ Standards were highly purified porcine glucagon (monocomponent Glucagon, NOVO Research Institute, Copenhagen). The gastrin antiserum (2604-8) is highly specific for gastrin and cross-reacts less than $0.1 \%$ with cholecystokinin. It does not bind any other hormones but binds the three large molecular forms of gastrin with equimolar potency. ${ }^{8}$ Synthetic human gastrin I was used as standard. The reliability parameters of the assay have been described elsewhere. ${ }^{9}$

Statistical evaluation of the data was performed by Student's $t$ test for paired observations. P values less than 0.05 were considered to be significant.

\section{Results}

Gastric acid secretion is shown in Fig. 1 and the Table. Pentagastrin in a submaximal dose $(150 \mathrm{ng} / \mathrm{kg} /$ min) significantly stimulated acid secretion pre- as well as postoperatively. Arginine infusion inhibited pentagastrin stimulated acid secretion significantly pre-operatively, but had no effect on acid secretion post-operatively.

Pancreatic glucagon was released to the same degree pre- and postoperatively (Fig. 2), and there was no differences in blood glucose concentrations (Fig. 3).

Serum-gastrin concentrations were significantly higher postoperatively but were unaffected by arginine infusion both pre- and postoperatively (Fig. 4).

\section{Discussion}

The present study shows that PCV eliminates the effect of endogenously released pancreatic glucagon on pentagastrin-stimulated acid secretion. PCV

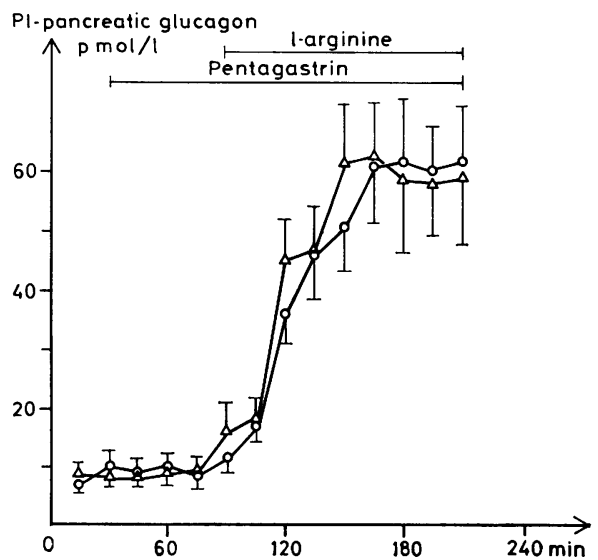

Fig. 2 Plasma-pancreatic glucagon concentrations pre- $(0-0)$ and postoperatively $(\triangle-\triangle)$. 


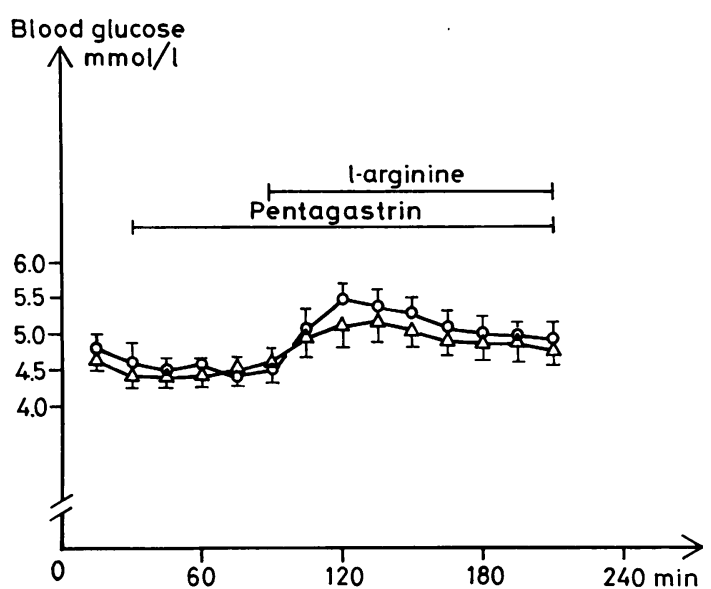

Fig. 3 Blood glucose concentrations pre- (0-0) and postoperatively $(\triangle-\triangle)$.

obviously interferes with the effect of glucagon on the parietal cells, as release of glucagon was unaltered as demonstrated by identical plasma concentrations pre- and postoperatively, fasting as well as during arginine infusion.

The dose of pentagastrin used is submaximal in unoperated patients with duodenal ulcer ${ }^{10}$ and, as vagotomy is followed by a decreased sensitivity to pentagastrin, ${ }^{11}$ this dose will also, and to a greater extent, be submaximal postoperatively; this means that the lack of effect of endogenous glucagon on pentagastrin stimulated acid secretion could not be explained simply by altered competitive interaction. This is further supported by studies showing that glucagon-pentagastrin interaction is non-competitive

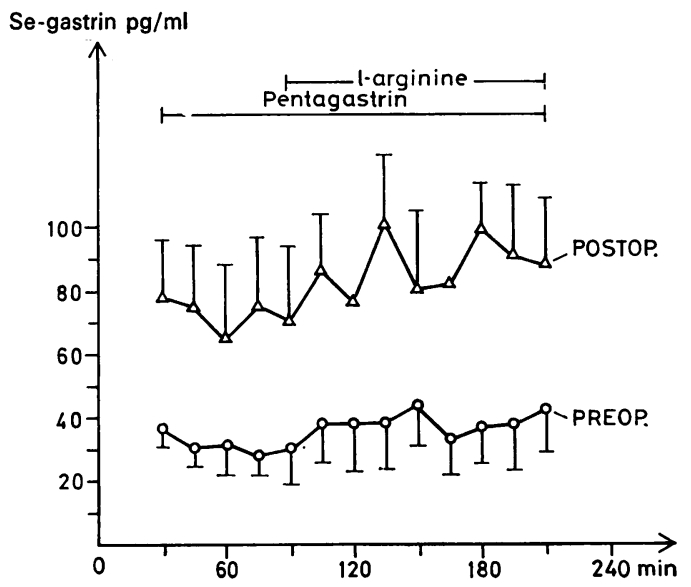

Fig. 4 Serum gastrin concentrations pre- and postoperatively. in healthy subjects, and that exogenous glucagon in doses resulting in plasma concentrations equal to meal-stimulated concentrations markedly inhibited supramaximal pentagastrin $(10 \mu \mathrm{g} / \mathrm{kg} / \mathrm{h})$ stimulated acid secretion in healthy subiects. ${ }^{1}$

Gastrin does not seem to be involved in this inhibitory mechanism, as serum-gastrin concentrations were unaltered by arginine infusion preand postoperatively. The increase in fasting serumgastrin after PCV was of the same magnitude as reported by others. ${ }^{12}$ It could be argued that the parietal cells after PCV are subject to a more intense intrinsic gastrin stimulation than before. These gastrin concentrations are, however, unlikely to be of importance compared with the dose of pentagastrin infused, and, furthermore, it was shown in a previous study that pancreatic glucagon in a 'physiological' dose inhibited the effect on acid secretion of synthetic human gastrin $I$ in doses resulting in serum-gastrin concentrations far above those found after PCV in the present study. ${ }^{1}$

The modest increase in blood glucose during arginine infusion can hardly affect vagal effect on acid secretion, as intravenous infusion of glucose in healthy subjects had no effect on pentagastrin stimulated acid secretion. ${ }^{13}$ The hypothesis could be advanced that pancreatic glucagon (or arginine) affects the local release of peptides or other transmitter substances from the vagus, a release which will not necessarily be reflected in raised plasma concentrations of these peptides. So far, however, there is no evidence for such a mechanism.

Recently, evidence was presented that somatostatin is a mediator of the enterogastrone effect of GIP. ${ }^{14}$ This does not seem to apply to glucagon, as studies in progress in our laboratory have shown that infusion of arginine decreases plasma somatostatin concentrations in duodenal ulcer patients both before and after PCV (four patients).

In conclusion, the study has demonstrated that the effect of endogenously released pancreatic glucagon on pentagastrin stimulated acid secretion is dependant on intact vagal innervation of the fundic glands. The mechanism of this vagus-glucagon interaction is obscure, but does not seem to involve gastrin or alterations in blood glucose.

This study was supported by the Danish Hospital Foundation for Medical Research. Region of Copenhagen, The Faroe Islands and Greenland.

\section{References}

${ }^{1}$ Christiansen J, Holst JJ, Kalaja E. Inhibition of gastric acid secretion in man by exogenous and endogenous pancreatic glucagon. Gastroenterology 1976; 70: 688-92. 
${ }^{2}$ Loud FB, Kirkegaard P, Holst JJ, Christiansen J. Effect of arginine infusion on endogenous pancreatic glucagon and gastric acid secretion in duodenal ulcer patients and normal subjects. Scand $J$ Gastroenterol 1980; 15: 711-4.

${ }^{3}$ Merimell TJ, Lillicrap DA, Rabinowitz D. Effect of arginine on serum levels of human growth hormone. Lancet 1965; 2: 668-70.

'Creutzfeldt W, Arnold R, Creutzfeldt C. Gastrin and G-cells in the central mucosa of patients with pernicious anemia, acromegaly and primary hyperparathyroidism and a Zollinger-Ellison tumour of the pancreas. Eur J Clin Invest 1971 ; 1 : 469-79.

${ }^{5}$ Christiansen J, Jensen H-E, Poulsen PE, Bardram L, Henriksen FW. A prospective controlled vagotomy trial for duodenal ulcer. Ann Surg. 1981; 193: 49-55.

'Widdonson GM, Penton JR. Determination of serum and plasma glucose on the 'out-analyzen II' by use of hexokinase reaction. Clin Chem 1972; 18: 299-300.

${ }^{7}$ Holst JJ. Evidence that glucagon contains the enteroglucagon sequence. Biochem $J$ 1980; 187: 337-43.

${ }^{8}$ Stadil F, Rehfeld JF. Radioimmunoassay of gastrin in linear serum. Scand J Gastroenterol 1971; 9 (suppl): 61-5.
'Stadil F, Rehfeld JF. Determination of gastrin in serum. An evaluation of the reliability of a radioimmunoassay. Scand J Gastroenterol 1973; 8: 101-12.

${ }^{10}$ Isenberg JI, Grossman MI, Maxwell V, Walsh JH. Increased sensitivity to stimulation of acid secretion by pentagastrin in duodenal ulcer. J Clin Invest 1975; 55: 330-7.

${ }^{11}$ Elder J, Gillespic BG, Campbell EHG, Gillespic IE, Creun GP, Kay AW. The effect of vagotomy on the lower port of the acid dose-response curve to pentagastrin in man. Clin Sci 1972; 43: 193-200.

${ }^{12}$ Donovan IA, Owens C, Clendinman BG, Griffin DW, Harding LK, Alexander-Williams J. Interrelations between serum gastrin levels, gastric emptying and acid output before and after proximal gastric vagotomy and truncal vagotomy and antrectomy. Br J Surg 1979; 66: 149-51.

${ }^{13}$ Holst JJ, Christiansen J. The effect of intravenous glucose on pentagastrin-induced gastric acid secretion in man. Acta Chir Scand 1975; 141 : 554-6.

${ }^{14}$ McIntosh CHS, Peterson RA, Brown JC. Gastric somatostatin as a mediator of the enterogastrone action of gastric inhibitory peptide (GIP). Reg Peptides 1980; suppl 1, 574. 